\title{
Tuning of the blue emission from europium-doped alkaline earth chloroborate thin films activated in air
}

\author{
Jianhua $\mathrm{Hao}^{\mathrm{a})}$ and J. Gao \\ Department of Physics, The University of Hong Kong, Pokfulam Road, Hong Kong \\ Michael Cocivera \\ Department of Chemistry, Thin-Film Semiconductor Laboratory, University of Guelph, Guelph, \\ Ontario N1G 2W1, Canada
}

(Received 3 September 2002; accepted 25 February 2003)

\begin{abstract}
Thin films of $\mathrm{M}_{2} \mathrm{~B}_{5} \mathrm{O}_{9} \mathrm{Cl}: \mathrm{Eu}(\mathrm{M}=\mathrm{Ca}, \mathrm{Sr}, \mathrm{Ba})$ were prepared on glass substrates using spray pyrolysis. Blue cathodoluminescence due to the abnormal reduction of $\mathrm{Eu}^{3+} \rightarrow \mathrm{Eu}^{2+}$ was obtained by annealing films in air. The cation of the host lattice was found to affect the effectiveness of the reduction process, which could result in influencing the emission band. By selecting types and composition of alkaline cation, it was possible to tune the dominant emitting wavelength between 435 to $465 \mathrm{~nm}$. Activation of the films occurred at temperatures suitable for the use of glass substrates. (C) 2003 American Institute of Physics. [DOI: 10.1063/1.1569048]
\end{abstract}

Blue luminescent properties have been of great interest for applications in flat-panel displays and optoelectronic devices. ${ }^{1-3}$ Selection of the emitting wavelength is required to meet requirements of some applications. ${ }^{2,4}$ Recently, development of oxide-based phosphors has received considerable attention due to their superior chemical and thermal stability. Some researchers ${ }^{5-8}$ have demonstrated the blue luminescent characteristics from alkaline earth element $(\mathrm{Sr}$, etc.) oxide-based hosts, such as $\mathrm{Sr}_{2} \mathrm{CeO}_{5}$ and $\mathrm{Sr}_{2} \mathrm{Al}_{5} \mathrm{O}_{25}$. In addition, our earlier work ${ }^{9,10}$ showed that thin films of Eudoped $\mathrm{Sr}_{2} \mathrm{~B}_{5} \mathrm{O}_{9} \mathrm{Cl}$ and $\mathrm{Ba}_{2} \mathrm{~B}_{5} \mathrm{O}_{9} \mathrm{Cl}$ had excellent chromaticity coordinates for blue phosphors. However, these phosphors exhibit blue specific to hosts and the dopants. There seems to be no report concerning the systematic adjustment of blue emission of oxide thin-film phosphors. In this letter, we report the tuning of the blue emission by changing cation type and composition in $\mathrm{M}_{2} \mathrm{~B}_{5} \mathrm{O}_{9} \mathrm{Cl}: \mathrm{Eu}(\mathrm{M}=\mathrm{Ca}, \mathrm{Sr}, \mathrm{Ba})$. Spray pyrolysis was used to deposit these thin films because it has some advantages over vacuum deposition in terms of tailoring materials composition and large-scale deposition. In particular, all blue phosphors in this work were activated in air at temperatures suitable for glass substrates, which are used in a number of applications, such as field-emission displays.

Thin films of $\mathrm{M}_{2} \mathrm{~B}_{5} \mathrm{O}_{9} \mathrm{Cl}(\mathrm{M}=\mathrm{Ca}, \mathrm{Sr}, \mathrm{Ba})$ doped with 2.0 at. $\% \mathrm{Eu}$ were prepared using spray pyrolysis of an aqueous solution containing $\mathrm{MCl}_{2}, \mathrm{H}_{3} \mathrm{BO}_{3}$, and $\mathrm{Eu}\left(\mathrm{OOCCH}_{3}\right)_{3}$. Excess $\mathrm{H}_{3} \mathrm{BO}_{3}$ was used in the precursor solution to compensate evaporation. The spray system was described in detail elsewhere. ${ }^{11,12}$ The Corning 7059 glass substrates used in our deposition had annealing and softening points of 639 and $844{ }^{\circ} \mathrm{C}$, respectively. The typical thickness of the film was around $1.2 \mu \mathrm{m}$. After deposition, thin films were annealed either at $800^{\circ} \mathrm{C}$ for $2 \mathrm{~min}$ in air by using a home-made rapid thermal annealing system, or at $630^{\circ} \mathrm{C}$ for $1 \mathrm{~h}$ in a tubefurnace. The cathodoluminescence (CL) and luminance measurements were as described earlier. ${ }^{9,10}$

a)Electronic mail: jhhao@hku.hk
Some of thin films were examined using x-ray diffraction techniques. ${ }^{9,10}$ Usually, as-grown films were apparently amorphous or consisted of very small crystallites. Annealed films formed a polycrystalline structure of $\mathrm{M}_{2} \mathrm{~B}_{5} \mathrm{O}_{9} \mathrm{Cl}: \mathrm{Eu}$. Scanning electron microscopy supported the conclusion. ${ }^{13}$

For the as-grown films of $\mathrm{M}_{2} \mathrm{~B}_{5} \mathrm{O}_{9} \mathrm{Cl}: \mathrm{Eu}$ deposited at $450{ }^{\circ} \mathrm{C}$, Fig. 1(a) shows the CL spectra at room temperature using a $5 \mathrm{kV}$ excitation voltage. The current density on the sample was measured to be $62 \mu \mathrm{A} / \mathrm{cm}^{2}$ for beam current of

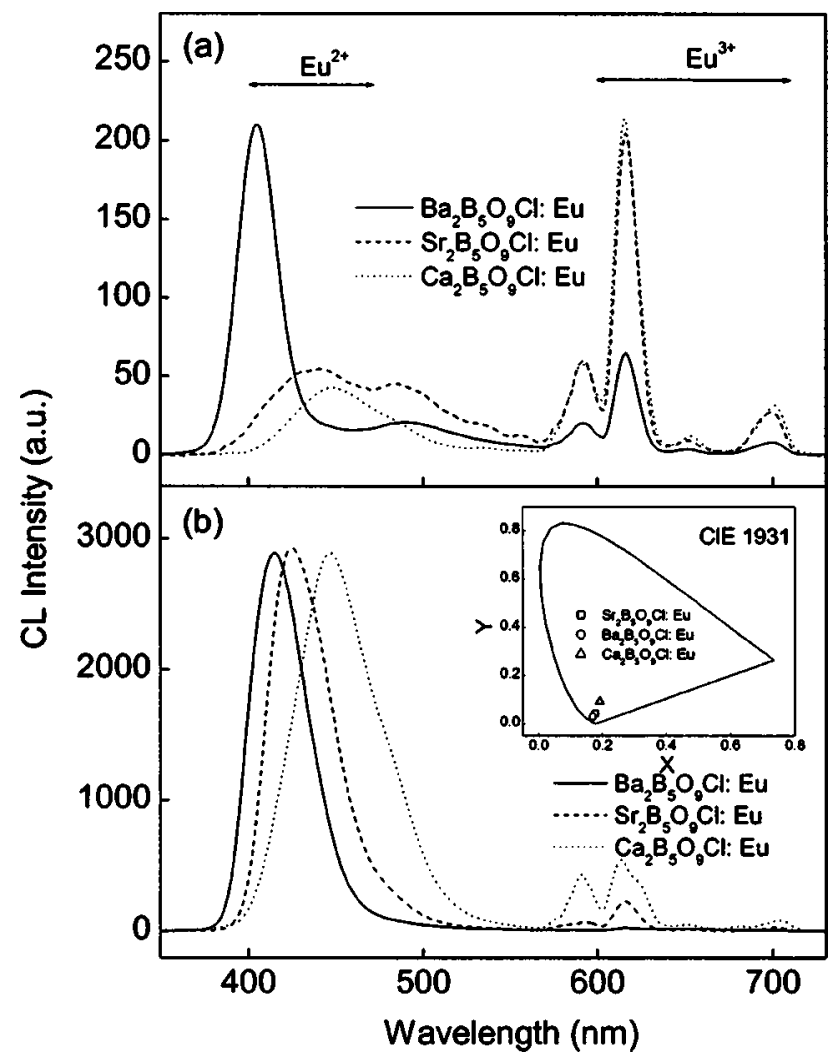

FIG. 1. CL for thin films of $\mathrm{M}_{2} \mathrm{~B}_{5} \mathrm{O}_{9} \mathrm{Cl}(\mathrm{M}=\mathrm{Ca}, \mathrm{Sr}, \mathrm{Ba})$ doped with $2 \%$ Eu: (a) as-grown at $450{ }^{\circ} \mathrm{C}$; and (b) deposited at $450{ }^{\circ} \mathrm{C}$ and annealed at $800{ }^{\circ} \mathrm{C}$ for $2 \mathrm{~min}$ in air. A CIE chromaticity diagram showing the chromaticity points of each film is presented in inset. 
TABLE I. Peak wavelength $\lambda_{\text {peak }}$, FWHM of CL spectra, chromaticity coordinates CIE, dominant wavelength $\lambda_{\text {domin }}$, and color purity compared to CIE Standard Source $\mathrm{C}$ for the CL of annealed films of $\mathrm{M}_{2} \mathrm{~B}_{5} \mathrm{O}_{9} \mathrm{Cl}$ :Eu (M $=\mathrm{Ba}, \mathrm{Sr}, \mathrm{Ca})$ and three mixed systems.

\begin{tabular}{lccccc}
\hline \hline \multicolumn{1}{c}{ Materials } & $\begin{array}{c}\lambda_{\text {peak }} \\
(\mathrm{nm})\end{array}$ & $\begin{array}{c}\text { FWHM } \\
(\mathrm{nm})\end{array}$ & $\begin{array}{c}\mathrm{CIE} \\
(x, y)\end{array}$ & $\begin{array}{c}\lambda_{\text {domin }} \\
(\mathrm{nm})\end{array}$ & $\begin{array}{c}\text { Color } \\
\text { Purity } \\
(\%)\end{array}$ \\
\hline $\mathrm{Ba}_{2} \mathrm{~B}_{5} \mathrm{O}_{9} \mathrm{Cl}: \mathrm{Eu}$ & 416 & 38 & $(0.171,0.029)$ & 435 & 95 \\
$\mathrm{Sr}_{2} \mathrm{~B}_{5} \mathrm{O}_{9} \mathrm{Cl}: \mathrm{Eu}$ & 425 & 42 & $(0.179,0.044)$ & 445 & 90 \\
$\mathrm{Ca}_{2} \mathrm{~B}_{5} \mathrm{O}_{9} \mathrm{Cl}: \mathrm{Eu}$ & 448 & 58 & $(0.193,0.099)$ & 465 & 77 \\
$(\mathrm{Sr}, \mathrm{Ca}) \mathrm{B}_{5} \mathrm{O}_{9} \mathrm{Cl}: \mathrm{Eu}$ & 439 & 49 & $(0.169,0.054)$ & 455 & 89 \\
$(\mathrm{Ba}, \mathrm{Ca}) \mathrm{B}_{5} \mathrm{O}_{9} \mathrm{Cl}: \mathrm{Eu}$ & 434 & 60 & $(0.207,0.101)$ & 450 & 73 \\
$(\mathrm{Sr}, \mathrm{Ba}) \mathrm{B}_{5} \mathrm{O}_{9} \mathrm{Cl}: \mathrm{Eu}$ & 421 & 38 & $(0.209,0.092)$ & 440 & 75 \\
\hline \hline
\end{tabular}

$0.5 \mathrm{~mA}$. The coexistence of CL spectra corresponding to transitions for both $\mathrm{Eu}^{3+}$ and $\mathrm{Eu}^{2+}$ was observed for all compounds. The amount of emission due to the $4 f^{7}$ $\rightarrow 4 f^{6} 5 d^{1}$ transition of $\mathrm{Eu}^{2+}$ followed the sequence of $\mathrm{Ba}$ $>\mathrm{Sr}>\mathrm{Ca}$. It is consistent with our previous studies on $\mathrm{Ba}_{2} \mathrm{~B}_{5} \mathrm{O}_{9} \mathrm{Cl}: \mathrm{Eu},{ }^{10}$ which have showed that the reduction of $\mathrm{Eu}^{3+}$ ions in $\mathrm{Ba}_{2} \mathrm{~B}_{5} \mathrm{O}_{9} \mathrm{Cl}: \mathrm{Eu}$ could occur at temperatures as low as $140{ }^{\circ} \mathrm{C} . \mathrm{Eu}^{3+}$ was found to be reduced to $\mathrm{Eu}^{2+}$ more efficiently in thin films of $\mathrm{Ba}_{2} \mathrm{~B}_{5} \mathrm{O}_{9} \mathrm{Cl}$. These results exhibit that the amount of $\mathrm{Eu}^{3+}$ reduced to $\mathrm{Eu}^{2+}$ increased when the ionic radius of the alkaline earth in the host was increased, indicating that the cation structures of borates have an influence on the electron transfer. Moreover, $\mathrm{Ba}_{2} \mathrm{~B}_{5} \mathrm{O}_{9} \mathrm{Cl}$ :Eu exhibited a relatively sharp peak due to the $\mathrm{Eu}^{2+}$ transition whereas $\mathrm{Ca}_{2} \mathrm{~B}_{5} \mathrm{O}_{9} \mathrm{Cl}$ :Eu and $\mathrm{Sr}_{2} \mathrm{~B}_{5} \mathrm{O}_{9} \mathrm{Cl}$ :Eu phosphors exhibited either a broad band or multibands. The single bands indicate that the $\mathrm{Eu}^{2+}$ might be located in one lattice site in $\mathrm{Ba}_{2} \mathrm{~B}_{5} \mathrm{O}_{9} \mathrm{Cl}: \mathrm{Eu}$ and $\mathrm{Ca}_{2} \mathrm{~B}_{5} \mathrm{O}_{9} \mathrm{Cl}: \mathrm{Eu}$, and multibands indicate that $\mathrm{Eu}^{2+}$ ion probably occupied more than one kind of center in the crystal.

Figure 1(b) shows the CL spectra of the compounds deposited at $450{ }^{\circ} \mathrm{C}$, and then annealed at $800^{\circ} \mathrm{C}$ for $2 \mathrm{~min}$ in air. Similar CL spectra were obtained for the films annealed at $630{ }^{\circ} \mathrm{C}$ for $1 \mathrm{~h}$. These spectra had an intense single sharp peak in the blue region along with weak peaks due to $\mathrm{Eu}^{3+}$ for each compound. The location of the color coordinates of each film on the CIE chromaticity diagram is presented in inset of Fig. 1(b). Table I lists peak wavelength, full width at half maximum (FWHM) of main peaks, chromaticity coordinates, dominant wavelength, and color purity compared to CIE Standard Source C for CL spectra of each annealed film. Obviously, the emission band shifts to longer wavelength and FWHM increases with decreasing ionic radius of the cation, that is, in the order $\mathrm{Ba}>\mathrm{Sr}>\mathrm{Ca}$. Peters and Baglio ${ }^{14}$ did pioneering work on the structural and luminescent properties of single-crystal alkaline earth chloroborates activated with europium. The results presented in Fig. 1 and Table I are in reasonable agreement with their data. However, our polycrystalline films had FWHM about 12-18 nm larger than those of the single-crystal samples, indicating that crystallinity and/or grain boundaries can affect luminescence features. Our data are also similar to those reported for powder samples of $\mathrm{M}_{2} \mathrm{~B}_{5} \mathrm{O}_{9} \mathrm{Cl}$ :Eu by other groups. ${ }^{15-17}$ It should be noted that all previously reported samples were prepared at high temperatures in a reducing atmosphere $\left(\mathrm{N}_{2} / \mathrm{H}_{2}\right)$ for the reduction of the $\mathrm{Eu}^{3+}$ to $\mathrm{Eu}^{2+}$. Thus, it is noteworthy that

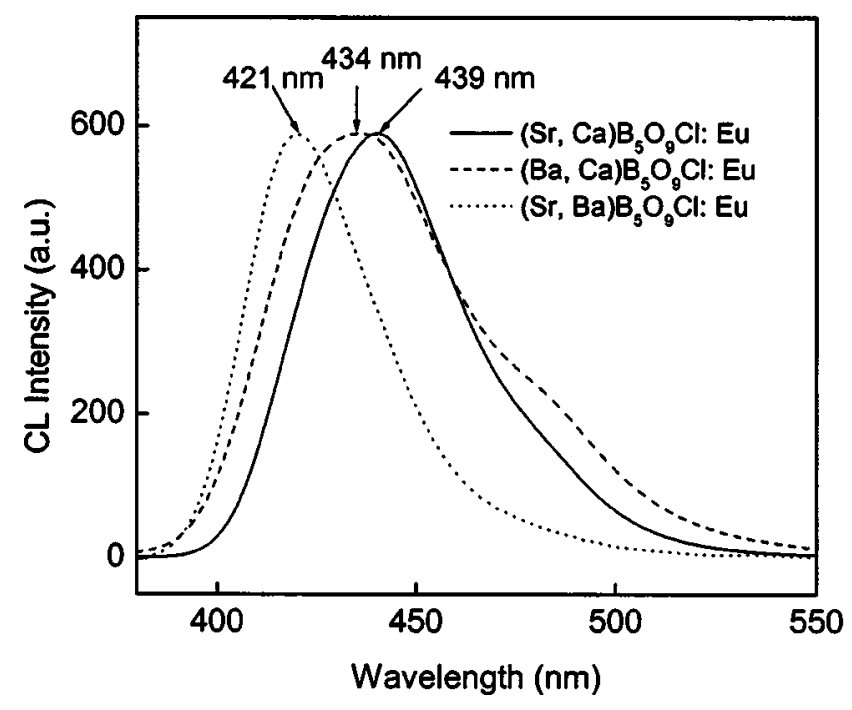

FIG. 2. CL for thin films of binary system of Eu-doped alkaline earth chloroborate deposited at $450{ }^{\circ} \mathrm{C}$ and annealed at $800{ }^{\circ} \mathrm{C}$ for $2 \mathrm{~min}$ in air.

our films of $\mathrm{M}_{2} \mathrm{~B}_{5} \mathrm{O}_{9} \mathrm{Cl}$ :Eu had blue emission when the films were annealed in air at temperatures suitable for the use of glass substrates. The abnormal reduction of $\mathrm{Eu}^{3+}+e$ $\rightarrow \mathrm{Eu}^{2+}$ could be related to the rigid three-dimensional network of $\mathrm{BO}_{4}$ tetrahedra, which is necessary to stabilize the divalent rare-earth ions in an oxidizing atmosphere. In the case of $\mathrm{M}_{2} \mathrm{~B}_{5} \mathrm{O}_{9} \mathrm{Cl}$ :Eu, boron atoms coordinate with three or four oxygen atoms to form $\mathrm{BO}_{3}$ and $\mathrm{BO}_{4}$ infrastructures, and these infrastructures comprise the $\left(\mathrm{B}_{5} \mathrm{O}_{9}\right)$ network. ${ }^{16}$ As a result, a negative $\mathrm{M}^{2+}$ vacancy was formed when three $\mathrm{M}^{2+}$ ions were replaced by only two $\mathrm{Eu}^{3+}$ ions. For this reason, the abnormal reduction was attributed to thermal stimulation of electron transfer from this defect to $\mathrm{Eu}^{3+}$. Usually, the reduction temperature of $\mathrm{Eu}^{3+}$ in borates depends on the structure of the boron units. However, the $\mathrm{Ba}_{2} \mathrm{~B}_{5} \mathrm{O}_{9} \mathrm{Cl}$ :Eu films produced more efficient monochromatic blue CL due to $\mathrm{Eu}^{2+}$ after thermal annealing in air compared with $\mathrm{Sr}_{2} \mathrm{~B}_{5} \mathrm{O}_{9} \mathrm{Cl}$ :Eu films. ${ }^{9,10}$ Consequently, the results shown in Fig. 1 provide further evidence that the cation of $\mathrm{M}_{2} \mathrm{~B}_{5} \mathrm{O}_{9} \mathrm{Cl}$ :Eu could affect the effectiveness of the reduction process.

Table I illustrates that the dominant and peak wavelength of $\mathrm{M}_{2} \mathrm{~B}_{5} \mathrm{O}_{9} \mathrm{Cl}$ :Eu shifted over a range of $30 \mathrm{~nm}$ as $\mathrm{M}$ changed from $\mathrm{Ca}$ to $\mathrm{Ba}$. This influence of the ionic radius of the alkaline earth ion on the emission band shift is attributed to a crystal-field effect. ${ }^{15,18}$ As the radius of the alkaline earth ion decreases, the crystal-field splitting of the $5 d$ level becomes larger. Consequently, a larger crystal-field splitting will shift the lowest $4 f^{6} 5 d$ state to lower energies. Because of this effect, the peak wavelength of the blue emission may be adjusted in the film by combining various alkaline earth ions in the compound. Figure 2 shows the main emission peaks of Eu-doped chloroborate thin films containing alkaline earth pairs deposited at $450{ }^{\circ} \mathrm{C}$ and annealed at $800{ }^{\circ} \mathrm{C}$ for $2 \mathrm{~min}$ in air. The parameters of the three mixed systems are also illustrated in Table I. The peak wavelengths of the three compounds are between the peak wavelengths of $\mathrm{Ba}_{2} \mathrm{~B}_{5} \mathrm{O}_{9} \mathrm{Cl}$ and $\mathrm{Ca}_{2} \mathrm{~B}_{5} \mathrm{O}_{9} \mathrm{Cl}$. The peak wavelengths of binary cation films are slightly longer than those calculated on the basis of cation atomic fractions. Additionally, the emis- 


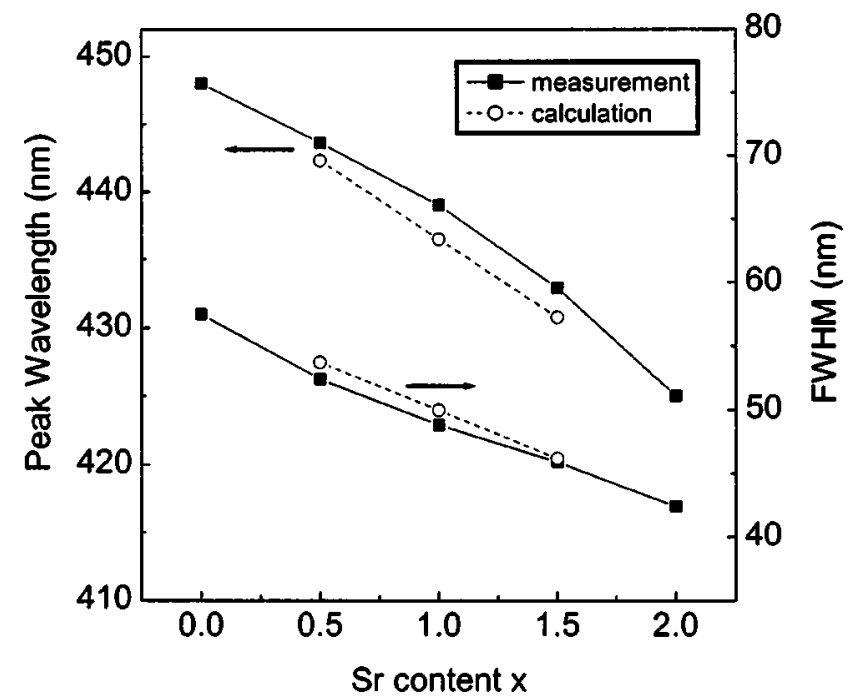

FIG. 3. The dependence of peak wavelength and FWHM on the Sr content $x$ in $\left(\mathrm{Sr}_{x} \mathrm{Ca}_{2-x}\right) \mathrm{B}_{5} \mathrm{O}_{9} \mathrm{Cl}$ :Eu annealed films.

sion bands of $(\mathrm{Sr}, \mathrm{Ba}) \mathrm{B}_{5} \mathrm{O}_{9} \mathrm{Cl}: \mathrm{Eu}$ and $(\mathrm{Sr}, \mathrm{Ca}) \mathrm{B}_{5} \mathrm{O}_{9} \mathrm{Cl}: \mathrm{Eu}$ are slightly narrower than calculated values. On the contrary, $(\mathrm{Ba}, \mathrm{Ca}) \mathrm{B}_{5} \mathrm{O}_{9} \mathrm{Cl}: \mathrm{Eu}$ had a larger FWHM value compared to the calculated one (60 versus $48 \mathrm{~nm}$ ), possibly because an unresolved shoulder existed at longer wavelength.

As an illustration, Fig. 3 shows the dependence of the peak wavelength and FWHM on the $\mathrm{Sr}$ content in $\left(\mathrm{Sr}_{x} \mathrm{Ca}_{2-x}\right) \mathrm{B}_{5} \mathrm{O}_{9} \mathrm{Cl}: \mathrm{Eu}$ films. All films were deposited at $450{ }^{\circ} \mathrm{C}$, and then annealed in air at $800^{\circ} \mathrm{C}$ for $2 \mathrm{~min}$. As expected, both peak wavelength and FWHM decrease when the $\mathrm{Sr}$ content increases. However, the measured values for peak wavelength are always larger and FWHM values are always smaller than those calculated on the basis of atomic fraction. The different efficiency of the alkaline earth ions in the mixed systems is probably the reason for the differences between experimental and calculated quantities. The combined effect of crystal-field splitting depends on the type and size of cation complexes. It has been established that with increasing radius of the host lattice cation in an isostructural series of compounds, the relaxation in the $4 f^{6} 5 d$ excited state of $\mathrm{Eu}^{2+}$ becomes more restricted. ${ }^{15}$ The smaller Stokes shift is also reflected in narrower emission bands with a smaller FWHM value. In addition, these deviations are likely related to the defects and/or impurity segregation at grain boundaries during the reaction of binary system. Those microstructures will either perturb the crystal field around the $\mathrm{Eu}^{2+}$ ion or introduce nonradiative traps in the band gap. ${ }^{19}$ More investigation is required to understand the exact mechanism.

In conclusion, thin-film blue phosphors of $\mathrm{M}_{2} \mathrm{~B}_{5} \mathrm{O}_{9} \mathrm{Cl}$ :Eu were prepared using spray pyrolysis of an aqueous solution. A change in type and/or composition of alkaline cation in compounds may alter the dominant wavelength from 435 to $465 \mathrm{~nm}$. This observation opens up a possibility of tuning blue emission of other alkaline earth oxide-based hosts by combining other alkaline earth elements, such as $\mathrm{Ca}$ and/or Ba. It is noteworthy that these films have been activated in air at temperatures suitable for the use of glass substrates.

${ }^{1}$ R. Y. Lee, F. L. Zhang, J. Penczek, B. K. Wagner, P. N. Yocom, and C. J. Summers, J. Vac. Sci. Technol. B 16, 855 (1998).

${ }^{2}$ High Brightness Light Emitting Diodes, edited by G. B. Stringfellow and M. G. Craford (Academic, San Diego, 1997).

${ }^{3}$ P. D. Rack and P. H. Holloway, Mater. Sci. Eng., R. 21, 171 (1998).

${ }^{4}$ W. M. Li, T. Hanninen, M. Leskela, J. Saari, and A. Hase, J. Alloys Compd. 323, 236 (2001).

${ }^{5}$ E. Danielson, M. Devenney, D. M. Giaquinta, J. H. Golden, R. C. Haushalter, E. W. McFarland, D. M. Poojary, C. M. Reaves, W. H. Weinberg, and X. D. Wu, Science 279, 837 (1998).

${ }^{6}$ Y. D. Jiang, F. Zhang, C. J. Summers, and Z. L. Wang, Appl. Phys. Lett. 74, 1677 (1999).

${ }^{7}$ Y. E. Lee, D. P. Norton, J. D. Budai, P. D. Rack, and M. D. Potter, Appl. Phys. Lett. 77, 678 (2000).

${ }^{8}$ Y. Lin, Z. Tang, Z. Zhang, and C. W. Nan, Appl. Phys. Lett. 81, 996 (2002).

${ }^{9}$ J. Hao and M. Cocivera, Appl. Phys. Lett. 79, 740 (2001).

${ }^{10}$ J. Hao and M. Cocivera, Appl. Phys. Lett. 81, 4154 (2002).

${ }^{11}$ N. Golego and M. Cocivera, Thin Solid Films 322, 14 (1998).

${ }^{12}$ J. Hao and M. Cocivera, J. Phys. D 35, 433 (2002).

${ }^{13}$ J. Hao and M. Cocivera, J. Phys.: Condens. Matter 14, 925 (2002).

${ }^{14}$ T. E. Peters and J. Baglio, J. Inorg. Nucl. Chem. 32, 1089 (1970).

${ }^{15}$ A. Meijerink and G. Blasse, J. Lumin. 43, 283 (1989).

${ }^{16}$ Z. Pu, M. Su, and S. Ruan, Mater. Res. Bull. 30, 1227 (1995).

${ }^{17}$ M. J. Knitel, B. Hommels, P. Dorenbos, C. W. E. van Eijk, I. Berezovskaya, and V. Dotsenko, Nucl. Instrum. Methods Phys. Res. A 449, 595 (2000).

${ }^{18}$ G. Blasse, Phys. Status Solidi B 55, K131 (1973).

${ }^{19}$ Y. E. Lee, D. P. Norton, and J. D. Budai, Appl. Phys. Lett. 74, 3155 (1999). 
Applied Physics Letters is copyrighted by the American Institute of Physics (AIP). Redistribution of journal material is subject to the AIP online journal license and/or AIP copyright. For more information, see http:/ojps.aip.org/aplo/aplcr.jsp

Copyright of Applied Physics Letters is the property of American Institute of Physics and its content may not be copied or emailed to multiple sites or posted to a listserv without the copyright holder's express written permission. However, users may print, download, or email articles for individual use. 